Check for updates

Cite this: RSC Adv., 2019, 9, 10727

Received 15th January 2019

Accepted 1st April 2019

DOI: $10.1039 / \mathrm{c} 9 \mathrm{ra00348g}$

rsc.li/rsc-advances

\title{
Investigation of the electrochemical oxidation of 2,3'-bisindolylmethanes in positive-ion electrospray ionization mass spectrometry $\dagger$
}

\begin{abstract}
$\mathrm{Xu} \mathrm{Xu},{ }^{\text {bd }}$ Guangyun He, ${ }^{\mathrm{b}}$ Xiaoying $\mathrm{Xu},{ }^{\mathrm{b}}$ Zhijun $\mathrm{Wu}^{\mathrm{c}}$ and Tian Cai $\mathbb{D}$ *a
Electrochemical reactions in electrospray may affect the electrospray ionization mass spectrometry (ESIMS) detection of the analytes. During ESI-MS analysis of 2,3'-bisindolylmethanes in the positive-ion mode, when methanol or acetonitrile was used as the solvent, electrochemical oxidation products as the dehydro and radical cations were observed. Lower sample introduction rates tended to result in a higher oxidation ratio of 2,3'-bisindolylmethanes. The ESI-MS experiments of 2,3'-bisindolylmethanes in different acetonitrile/methanol solvent mixtures indicated that abundant $\mathrm{H}^{+}, \mathrm{Na}^{+}$or $\mathrm{K}^{+}$would facilitate the adduct formation process, and otherwise electrochemical oxidation dominated the ionization process. Additionally, when dichloromethane was used as the solvent, $[\mathrm{M}-3 \mathrm{H}]^{+},[\mathrm{M}-2 \mathrm{H}]^{+\cdot}$ and $[\mathrm{M}-$ $3 \mathrm{H}+\mathrm{O}^{+}$ions are the predominant ions, and the experimental results revealed that the dehydrogenation and oxidative dehydrogenation reactions of $2,3^{\prime}$-bisindolylmethanes in dichloromethane are electrochemical reactions.
\end{abstract}

\section{Introduction}

Electrospray ionization (ESI) is one of the most prominent techniques to accomplish the transfer of analytes from solution to the gas phase under atmospheric pressure. Electrospray ionization mass spectrometry (ESI-MS) can deal well with medium polar to ionic molecules, and has been widely used in the fields of organic, medicinal and biological chemistry, etc. In general, quasi-molecular ions $[\mathrm{M}+\mathrm{H}]^{+},[\mathrm{M}+\mathrm{Na}]^{+}$and $[\mathrm{M}+\mathrm{K}]^{+}$in positive-ion mode, and $[\mathrm{M}-\mathrm{H}]^{-},[\mathrm{M}+\mathrm{Cl}]^{-}$and $[\mathrm{M}+\mathrm{HCOO}]^{-}$in negative-ion mode are observed in ESI-MS. ${ }^{1,2}$

In an ESI source, an electrospray plume is produced by applying a potential difference of $\pm 3-6 \mathrm{kV}$, and the electrospray can be considered as an electrochemical cell. ${ }^{3-6}$ The occurrence of electrochemical redox reactions in ESI source may result in several unexpected ions, such as radical ions, $[\mathrm{M}-\mathrm{H}]^{+},[\mathrm{M}+$ $\mathrm{H}]^{-}$ions, and so on. Certain unpredictable electrochemical reactions may make mistakes on the molecular weight of the analytes and even make the mass spectral background complicated, leading to false qualitative and quantitative

${ }^{a}$ School of Chemistry and Chemical Engineering, Southwest University, Beibei, Chongqing, 400715, China. E-mail: caitian@swu.edu.cn

${ }^{b}$ Chengdu Institute of Organic Chemistry, University of Chinese Academy of Sciences, Chengdu 610041, China

${ }^{c}$ Chengdu Institute of Biology, University of Chinese Academy of Sciences, Chengdu 610041, China

${ }^{d}$ University of Chinese Academy of Sciences, Beijing 100039, China

† Electronic supplementary information (ESI) available. See DOI: 10.1039/c9ra00348g analysis. ${ }^{7}$ Several strategies have been proposed to reduce these undesirable electrochemical reactions during the ESI-MS analysis. ${ }^{8-11}$ Furthermore, appropriate electrochemical redox reactions might also be utilized to improve the detection sensitivity of the analytes with poor ESI response using conventional analytical methods. For example, it is difficult to generate stable $[\mathrm{M}+\mathrm{H}]^{+}$and $[\mathrm{M}-\mathrm{H}]^{-}$ions from halobenzoquinones during ESI process, however, $\mathrm{M}^{-\cdot}$ and $[\mathrm{M}+\mathrm{H}]^{-}$ions are detected with high abundance, which was developed to determine trace levels of halobenzoquinones in water samples. ${ }^{12,13}$ Therefore, the investigation of the electrochemical reactions in ESI source is of scientific significance.

There are various factors that affect the electrochemical processes in the ESI source, including the chemical properties of the analytes, the solvent system ${ }^{\mathbf{1 4}}$ and the ESI source conditions, etc. In our previous report, 2,3'-bisindolylmethanes were analyzed using ESI-MS positive-ion mode with methanol as the solvent, and electrochemical oxidation products as $[\mathrm{M}]^{+\bullet}$ and $[\mathrm{M}$ $-\mathrm{H}]^{+}$ions were observed. ${ }^{15}$ While using dichloromethane as the solvent, unexpected $[\mathrm{M}-3 \mathrm{H}]^{+},[\mathrm{M}-2 \mathrm{H}]^{+\cdot}$ and $[\mathrm{M}+13]^{+}$ions were generated. Herein, the factors that affect the oxidation of 2,3'-bisindolylmethanes during the electrospray process were investigated.

\section{Experimental}

High-performance liquid chromatography-grade methanol and acetonitrile were procured from J\&K Scientific Ltd. (Beijing, China). High-performance liquid chromatography-grade dichloromethane and dichloromethane- $d_{2}$ were purchased 


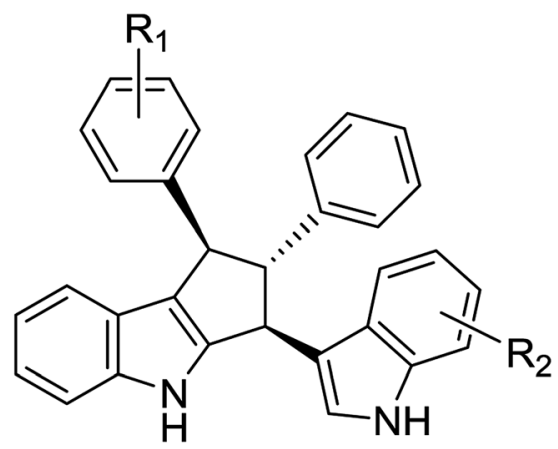

1. $\mathrm{R}_{1}=\mathrm{R}_{2}=\mathrm{H}, \mathrm{C}_{31} \mathrm{H}_{24} \mathrm{~N}_{2}, M r 424.1939$

2. $\mathrm{R}_{1}=\mathrm{H}, \mathrm{R}_{2}=6-\mathrm{F}, \mathrm{C}_{31} \mathrm{H}_{23} \mathrm{FN}_{2}, M r 442.1845$

3. $\mathrm{R}_{1}=2-\mathrm{F}, \mathrm{R}_{2}=\mathrm{H}, \mathrm{C}_{31} \mathrm{H}_{23} \mathrm{FN}_{2}, \mathrm{Mr} 442.1845$

4. $\mathrm{R}_{1}=\mathrm{H}, \mathrm{R}_{2}=\mathrm{CH}_{3}, \mathrm{C}_{32} \mathrm{H}_{26} \mathrm{~N}_{2}, \mathrm{Mr} 438.2096$

Scheme 1 Structures of 2,3'-bisindolylmethanes.

from Chengdu Kelong Chemical Co., Ltd. (Chengdu, China) and Cambridge Isotope Laboratories (Andover, MA, USA), respectively. The 2,3'-bisindolylmethanes (compounds 1-4 shown in Scheme 1) were obtained from Guo's laboratory. ${ }^{16}$ MS experiments were performed on a quadrupole time-of-flight (QTOF) mass spectrometer (Bruker Impact II, Bremen, Germany). The mass resolution was about 59500 FWHM (full width at half maximum) at $1222 \mathrm{u}$. High-purity nitrogen was used as the nebulizer, dry gas and collision gas. The conditions of ESI source in positive-ion mode were as follows: capillary voltage, $4500 \mathrm{~V}$; end plate offset, $500 \mathrm{~V}$; nebulizer, 0.4 bar; dry gas, 4.0 $\mathrm{L} \min ^{-1}$ and the dry gas temperature, $180{ }^{\circ} \mathrm{C}$. The sample solution was introduced at a rate of $180 \mu \mathrm{L} \mathrm{h}^{-1}$ by a peristaltic pump. The mass data were processed by Bruker Compass Data Analysis 4.4.

\section{Results and discussion}

Several 2,3'-bisindolylmethanes (Scheme 1) were analyzed using ESI-MS in positive-ion mode under various detecting conditions. Similar results were obtained for all compounds, and compound $\mathbf{1}$ was selected as a representative compound for the following discussion. Its full-scan mass spectra obtained by adopting different spray solvents were shown in Fig. 1.

\section{Solvent: methanol}

When methanol was used as the solvent, as shown in Fig. 1(A), the dehydro cation at $m / z 423$, the radical cation at $m / z 424$, the sodium adduct ion at $\mathrm{m} / \mathrm{z} 447$ and the potassium adduct ion at $\mathrm{m} / \mathrm{z} 463$ were observed. Notably, Fig. 1(B) revealed that the dehydro and radical cations were basically immune to $\mathrm{H}_{2} \mathrm{O}$ in solvent. In fact, both of the dehydro and radical cations could be regarded as the oxidation species of compound 1 in the ESI source. Herein, oxidation ratio is used to describe the degree of oxidation of compound 1 in ESI-MS, which was defined as the ratio of the signal intensity of the oxidation species to that of all ions derived from compound 1, including $[\mathrm{M}+\mathrm{H}]^{+},[\mathrm{M}+\mathrm{Na}]^{+}$ and $[\mathrm{M}+\mathrm{K}]^{+}$as well as the dehydro and radical cations.

The effect of the sample introduction rate on dehydro and radical cations was investigated, and as shown in Fig. 2(A), the corresponding oxidation ratio decreased gradually with the increase of the sample introduction rate. Obviously, lower sample introduction rate prolonged the contact time between the analyte solution and the surface of the metal capillary, contributing to electrochemical oxidation reaction. Generally, increasing ionization voltages tended to promote the electrochemical oxidation reaction, and the effect of capillary voltages on oxidation ratio was also implemented. As shown in Fig. 2(B), the oxidation ratio increased slightly with the capillary voltage from 3.5 to $5.5 \mathrm{kV}$, followed by a sudden rise when the capillary voltage reached $6.0 \mathrm{kV}$.

\section{Solvent: acetonitrile}

When acetonitrile was used as the solvent, the dehydro and radical cations were observed with highest abundance in the full-scan mass spectrum, while the peaks of adduct ions including $[\mathrm{M}+\mathrm{H}]^{+},[\mathrm{M}+\mathrm{Na}]^{+}$and $[\mathrm{M}+\mathrm{K}]^{+}$were almost invisible for compound 1 (see Fig. 1(C)). Interestingly, two new peaks at $\mathrm{m} / z 421.1702$ and $\mathrm{m} / z 422.1768$ were also detected, identified as $\mathrm{C}_{31} \mathrm{H}_{21} \mathrm{~N}_{2}$ and $\mathrm{C}_{31} \mathrm{H}_{22} \mathrm{~N}_{2}$, respectively. By comparison with the full-scan mass spectrum of blank acetonitrile, the ion peaks at $\mathrm{m} / \mathrm{z} 421$ and $\mathrm{m} / \mathrm{z} 422$ in Fig. 1(C) were confirmed as two other oxidation products from compound $1,[\mathrm{M}-3 \mathrm{H}]^{+}$and $[\mathrm{M}-$ $2 \mathrm{H}]^{+}$, respectively. Comparing Fig. 1(A) and (C), it was easy to find that the spray solvents, methanol and acetonitrile, have significant influence on the profiles of mass spectra of compound 1.

\section{Solvent mixture: methanol \& acetonitrile}

To gain more insights into the solvent effect on electrochemical reactions for compound $\mathbf{1}$ in the ESI source, the ESI-MS experiments of compound $\mathbf{1}$ in mixed solvents with different volume ratios of methanol/acetonitrile were carried out. As the methanol proportion of the mixed solvent rose, the oxidation ratio of compound 1 decreased, as shown in Fig. 3, revealing that the compound $\mathbf{1}$ in acetonitrile was more easily oxidized than that in methanol. Essentially, in the positive ion mode of ESI-MS, compound 1 can be charged through eight possible pathways in the electrospray process (Scheme 2(B)). Pathways $\mathrm{i}-\mathrm{v}$ are electrochemical oxidation processes, while pathways vi-viii are adduct formation processes. Compared with acetonitrile, methanol contains more $\mathrm{Na}^{+}$or $\mathrm{K}^{+},{ }^{17}$ and the adduct formation processes are the main ionization paths of compound 1 with methanol as the spray solvent during the electrospray 

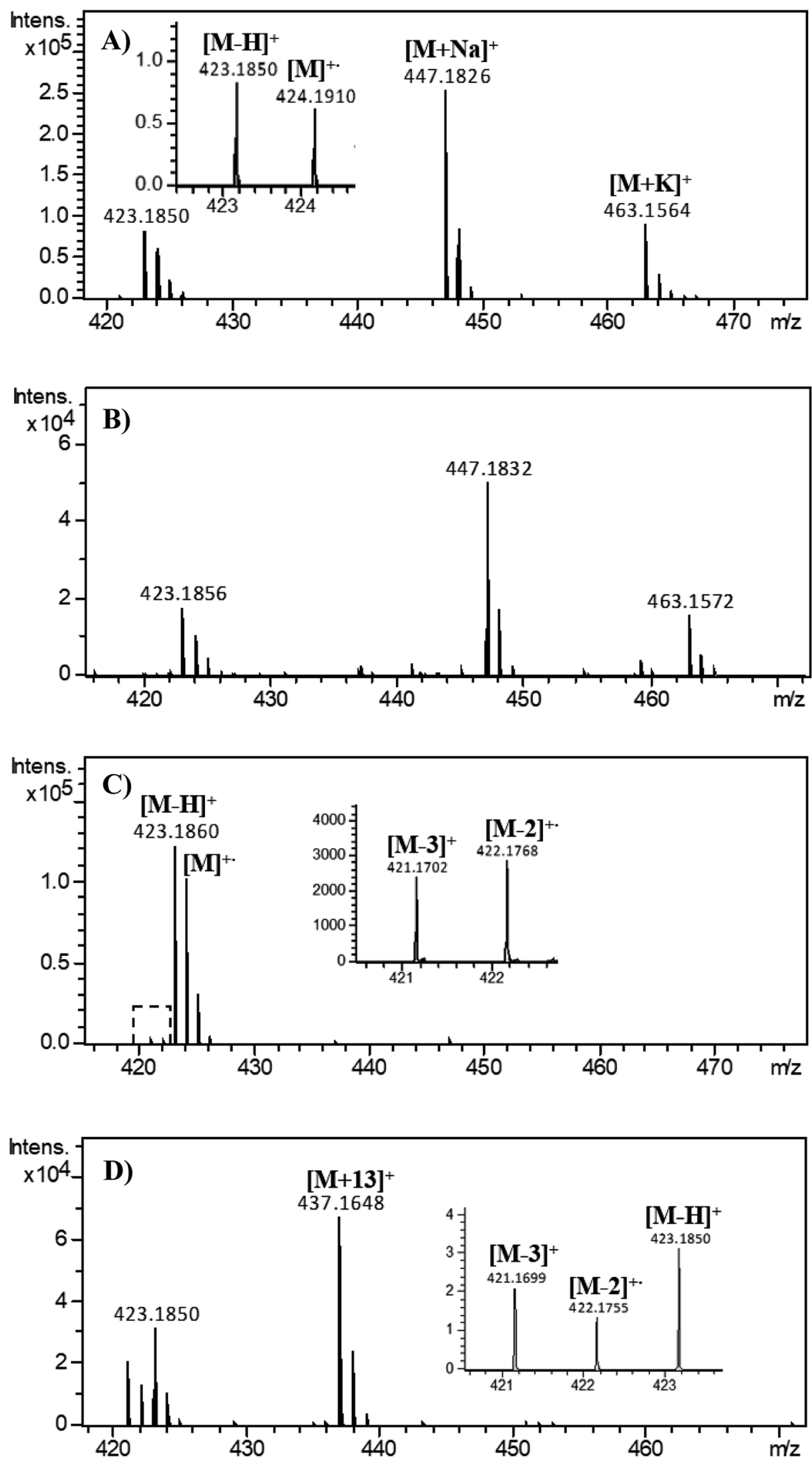

Fig. 1 The full-scan mass spectra of compound 1 in (A) methanol; (B) methanol and water (9:1, v/v); (C) acetonitrile; (D) dichloromethane. 
A)
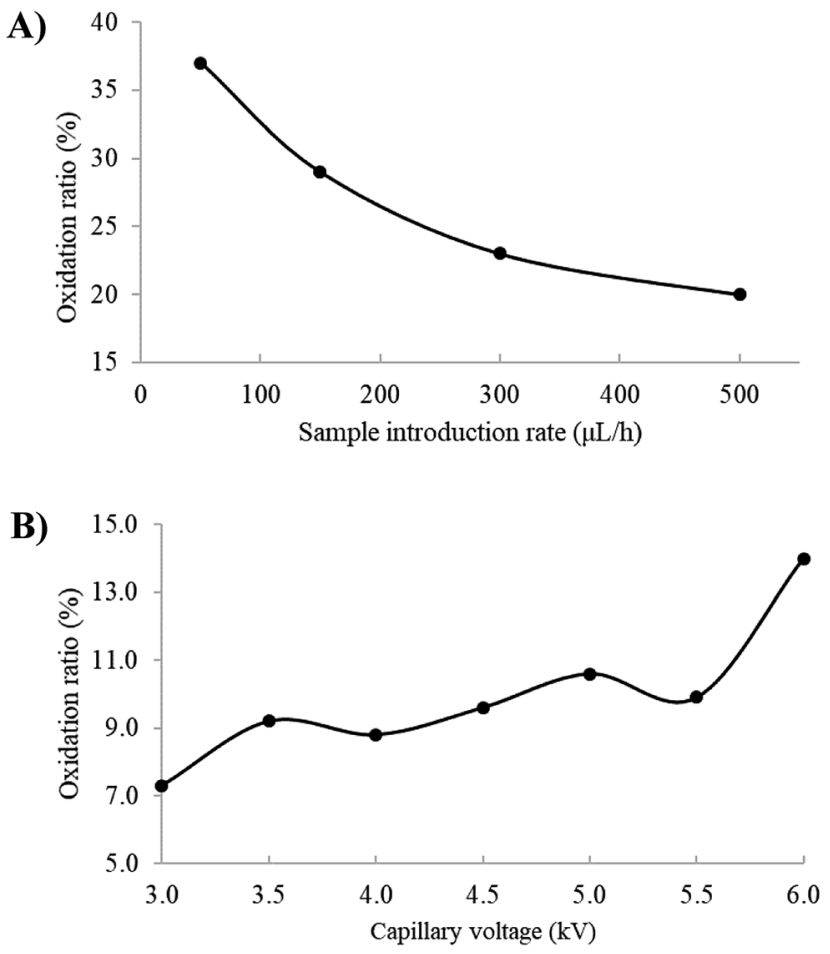

Fig. 2 When methanol was used as the solvent, plot of oxidation ratio (\%) of compound 1 versus (A) sample introduction rate over the range from $50-500 \mu \mathrm{L} \mathrm{h}^{-1}$; (B) capillary voltage from 3.0 to $6.0 \mathrm{kV}$. Oxidation ratio $(\%)=\left(I_{[\mathrm{M}-\mathrm{H}]^{+}}+I_{[\mathrm{M}]^{+}}\right) /\left(I_{[\mathrm{M}-\mathrm{H}]^{+}}+I_{[\mathrm{M}]^{+}}+I_{[\mathrm{M}+\mathrm{H}]^{+}}+I_{[\mathrm{M}+\mathrm{Na}]^{+}}+I_{[\mathrm{M}+\mathrm{K}]^{+}}\right) \times$ $100 \%$.

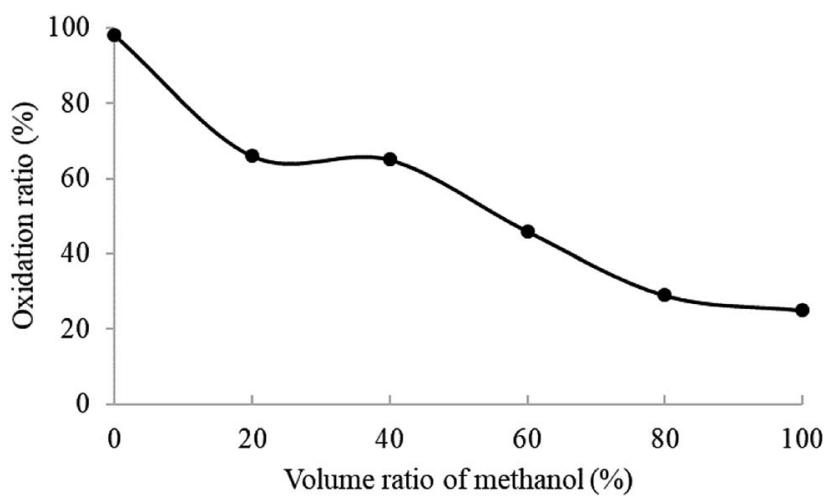

Fig. 3 Plot of oxidation ratio (\%) of compound 1 versus the volume proportion of methanol in acetonitrile/methanol solvent mixtures.

ionization process. This indicates that if the spray solvent contains less ionic species, compound $\mathbf{1}$ may be easily ionized through electrochemical oxidation processes. In order to verify this speculation, the effect of $\mathrm{K}_{2} \mathrm{CO}_{3}$ addition on the abundance of $[\mathrm{M}-\mathrm{H}]^{+}$at $m / z 423$ for compound $\mathbf{1}$ with acetonitrile as the solvent was investigated (Fig. S4 $\dagger$ ). The relative abundance of [M $-\mathrm{H}]^{+}$at $m / z 423$ decreased as the content of $\mathrm{K}_{2} \mathrm{CO}_{3}$ increases.

\section{Solvent: dichloromethane}

Dichloromethane is used extensively in organic synthesis and separations, and therefore the ESI-MS experiments of 2,3'bisindolylmethanes with dichloromethane as the solvent were also carried out. As shown in Fig. 1(D), similar ion peaks at $\mathrm{m} / \mathrm{z}$ 421 and $\mathrm{m} / z 422$ were also observed with high abundance in the full-scan mass spectrum of compound 1. Additionally, an unexpected ion at $\mathrm{m} / \mathrm{z} 437$ was observed with very high abundance, and high-resolution observation of the peak $(\mathrm{m} / \mathrm{z}$ 437.1648) suggests $\mathrm{C}_{31} \mathrm{H}_{21} \mathrm{~N}_{2} \mathrm{O}$ (Table $\mathrm{S} 2 \dagger$ ) confirmed as [M $3 \mathrm{H}+\mathrm{O}]^{+}$of compound 1. The MS/MS spectrum of $[\mathrm{M}-2 \mathrm{H}]^{+}$. (Fig. S6(A) $\dagger$ ) revealed that $[\mathrm{M}-3 \mathrm{H}]^{+}$was not generated from $[\mathrm{M}$ $-2 \mathrm{H}]^{+\cdot}$ by the loss of a $\mathrm{H}$ radical. No detection of $[\mathrm{M}-3 \mathrm{H}]^{+}$ion in MS/MS spectra of $[\mathrm{M}-\mathrm{H}]^{+}$and $[\mathrm{M}+\mathrm{H}]^{+}$(ref. 15) indicated that $[\mathrm{M}-3 \mathrm{H}]^{+}$ion was not formed from $[\mathrm{M}-\mathrm{H}]^{+}$or $[\mathrm{M}+\mathrm{H}]^{+}$via the loss of $\mathrm{H}_{2}$ or $2 \mathrm{H}_{2}$, respectively, but from compound 1 losing $\mathrm{H}_{2}$ followed by the immediate loss of a hydride anion. Two main fragment ions at $m / z 419$ and 343 were produced by the loss of a $\mathrm{H}_{2}$ or $\mathrm{C}_{6} \mathrm{H}_{6}$, respectively, from the $[\mathrm{M}-3 \mathrm{H}]^{+}$ion at $\mathrm{m} / z 421$ under higher collision energy (Fig. S6(B) $\dagger$ ), and the $[\mathrm{M}-3 \mathrm{H}+$ $\mathrm{O}^{+}$ion at $\mathrm{m} / z 437$ was easily dissociated into abundant fragment ions (Fig. S6(C) †), which indicated that oxidation destroyed the stability of the compound 1 . The possible structures of $[\mathrm{M}-2 \mathrm{H}]^{+*},[\mathrm{M}-3 \mathrm{H}]^{+}$and $[\mathrm{M}-3 \mathrm{H}+\mathrm{O}]^{+}$for compound 1 were shown in Scheme 2(A), and their detail fragmentation pathways were shown in Scheme S1.† Moreover, in the ESI-MS analysis of compounds $\mathbf{2 - 4}$, similar phenomena were also observed. These experimental phenomena revealed that compared to acetonitrile and methanol, compound 1 $\left(\mathrm{C}_{31} \mathrm{H}_{24} \mathrm{~N}_{2}\right)$ in dichloromethane tended to more easily generate $\mathrm{C}_{31} \mathrm{H}_{22} \mathrm{~N}_{2}$ and $\mathrm{C}_{31} \mathrm{H}_{22} \mathrm{~N}_{2} \mathrm{O}$ through dehydrogenation and oxidative dehydrogenation reactions, respectively. Although the oxidation reaction of compound $\mathbf{1}$ proceeded thoroughly in both acetonitrile and dichloromethane, compound $\mathbf{1}$ was more easily dehydrogenated in dichloromethane during the electrospray process. Compared with acetonitrile, dichloromethane has lower polarity, and thus for compound $\mathbf{1}$, low polar solvent may facilitate dehydrogenation.

During the ESI process, there are two main factors that may lead to the dehydrogenation or oxidative dehydrogenation reaction of compound $\mathbf{1}$ in dichloromethane, i.e., hightemperature drying gas and high needle voltage. When the electrospray needle voltage was maintained at $4.5 \mathrm{kV}$, as the drying gas temperature increased from 50 to $350{ }^{\circ} \mathrm{C}$, insignificant changes in abundance of $\mathrm{m} / \mathrm{z} 421, \mathrm{~m} / \mathrm{z} 422$ and $\mathrm{m} / \mathrm{z} 437$ ions were observed. Furthermore, the nuclear magnetic resonance (NMR) experiments with dichloromethane- $d_{2}$ (Fig. S4, ESI $\dagger$ ) as the solvent indicated that the structure of compound 1 did not change in dichloromethane. Therefore, the dehydrogenation and oxidative dehydrogenation reactions of compound 1 in dichloromethane should be involved in electrochemical reactions during the electrospray ionization process. 
A)<smiles></smiles>

[M-3H] $]^{+}: \mathrm{C}_{31} \mathrm{H}_{21} \mathrm{~N}_{2}$ $\mathrm{m} / \mathrm{z}: 421$

B)

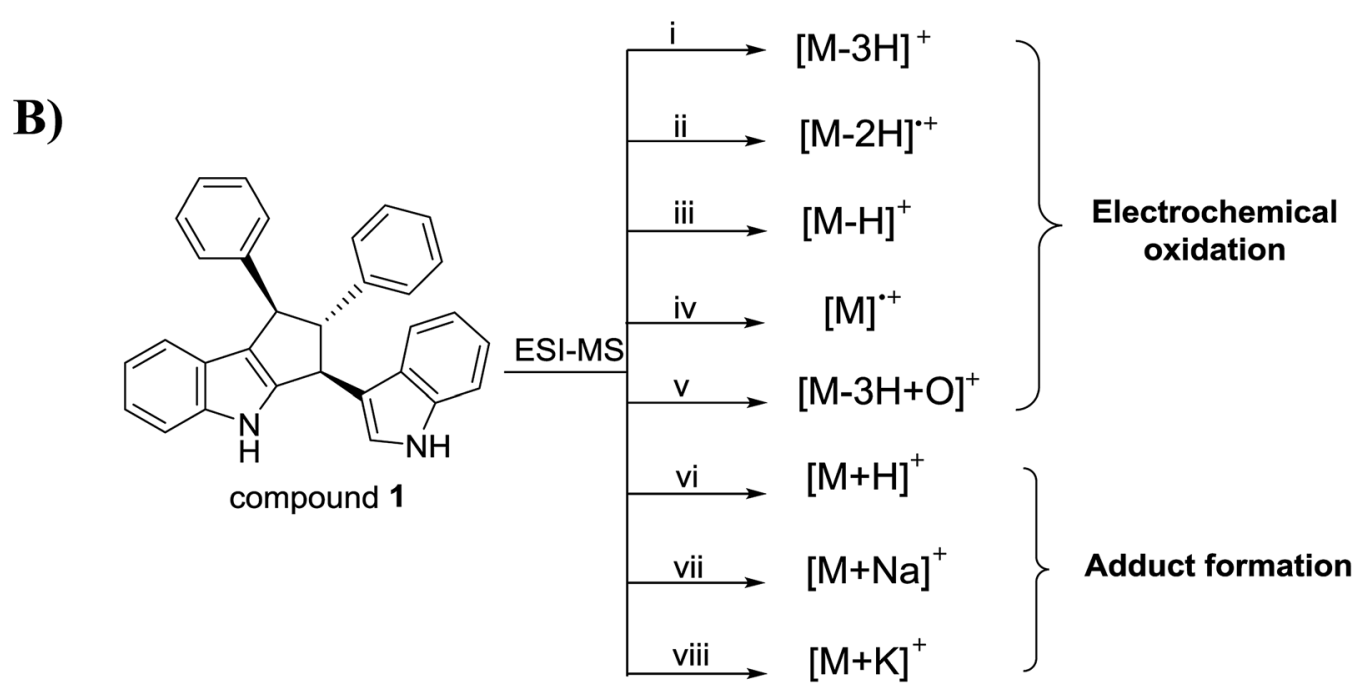

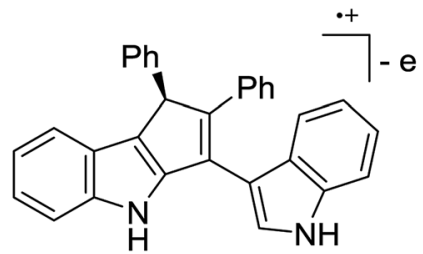

or

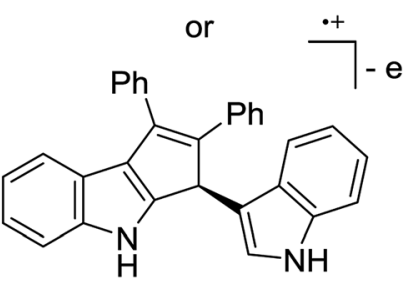

$\left[\mathrm{M}-2 \mathrm{H}^{+\cdot}: \mathrm{C}_{31} \mathrm{H}_{22} \mathrm{~N}_{2}\right.$ $\mathrm{m} / \mathrm{z} 422$<smiles>C1=C2Nc3ccccc3[C@H]2c2[nH]c3ccccc3c2[C@H]1c1ccccc1</smiles>

or<smiles>c1ccc(C23OC2(c2ccccc2)[C@H](c2c[nH]c4ccccc24)c2[nH]c4ccccc4c23)cc1</smiles>

[M-3H+O] ${ }^{+}: \mathrm{C}_{31} \mathrm{H}_{21} \mathrm{~N}_{2} \mathrm{O}$

$\mathrm{m} / \mathrm{z} 437$

Scheme 2 (A) The possible structures of $[\mathrm{M}-3 \mathrm{H}]^{+},[\mathrm{M}-2 \mathrm{H}]^{+\cdot}$ and $[\mathrm{M}-3 \mathrm{H}+\mathrm{O}]^{+}$, respectively; (B) eight possible ionization pathways of compound 1 in positive-ion ESI-MS.

\section{Conclusions}

In this study, the oxidation of 2,3'-bisindolylmethanes during electrospray ionization mass spectrometry (ESI-MS) in positive ion mode was investigated. The signal intensity of the dehydro and radical cations from compound $\mathbf{1}$ decreased as the proportion of methanol in different acetonitrile/methanol solvent mixtures increased, revealing that ionic species, such as $\mathrm{H}^{+}, \mathrm{Na}^{+}$or $\mathrm{K}^{+}$, in the solvent would facilitate the adduct formation process, and otherwise electrochemical oxidation dominated the ionization process. When dichloromethane was used as the solvent, the dehydrogenation and oxidative dehydrogenation reactions of $2,3^{\prime}$-bisindolylmethanes were involved in electrochemical reactions in the electrospray. This work permits us to highlight the importance of investigation of electrochemical transformations occurring in the electrospray emitter, which is helpful for understanding the ionization process of electrospray ionization. Moreover, and electrospray may be employed as an electrolytic flow cell to promote several chemical reactions.

\section{Conflicts of interest}

There are no conflicts to declare.

\section{Acknowledgements}

This work was supported by the National Natural Science Foundation of China (No. 21305137).

\section{References}

1 R. B. Cole, J. Mass Spectrom., 2000, 35, 763-772.

2 P. Kebarle, J. Mass Spectrom., 2000, 35, 804-817.

3 A. T. Blades, M. G. Ikonomou and P. Kebarle, Anal. Chem., 1991, 63, 2109-2114. 
4 G. J. Van Berkel and V. Kertesz, Anal. Chem., 2007, 79, 55105520.

5 M. Abonnenc, L. Qiao, B. H. Liu and H. H. Girault, Annu. Rev. Anal. Chem., 2010, 3, 231-254.

6 B. P. Pozniak and R. B. Cole, J. Am. Soc. Mass Spectrom., 2015, 26, 369-385.

7 Y. F. Chai, H. Z. Sun, J. P. Wan, Y. J. Pan and C. R. Sun, Analyst, 2011, 136, 4667-4669.

8 G. J. Van Berkel and F. M. Zhou, Anal. Chem., 1995, 67, 29162923.

9 E. Peintler-Krivan, G. J. Van Berkel and V. Kertesz, Rapid Commun. Mass Spectrom., 2010, 24, 1327-1334.

10 S. Plattner, R. Erb, J. P. Chervet and H. Oberacher, Anal. Bioanal. Chem., 2012, 404, 1571-1579.
11 V. Kertesz and G. J. Van Berkel, Int. J. Mass Spectrom., 2011, 303, 206-211.

12 F. Qin, Y. Y. Zhao, Y. L. Zhao, J. M. Boyd, W. J. Zhou and X. F. Li, Angew. Chem., Int. Ed., 2010, 49, 790-792.

13 R. F. Huang, W. Wang, Y. C. Qian, J. M. Boyd, Y. L. Zhao and X. F. Li, Anal. Chem., 2013, 85, 4520-4529.

14 G. J. Van Berkel, S. A. McLuckey and G. L. Glish, Anal. Chem., 1992, 64, 1586-1593.

15 G. Y. He, T. Cai, X. Y. Xu, D. M. Fang and Z. J. Wu, Int. J. Mass Spectrom., 2016, 410, 63-67.

16 C. Zhang, L. X. Zhang, Y. Qiu, B. Xu, Y. Zong and Q. X. Guo, RSC Adv., 2014, 4, 6916-6919.

17 S. P. Pinho and E. A. Macedo, J. Chem. Eng. Data, 2005, 50, 29-32. 